\title{
Unfilled Hunger: Seeking Relationships in Primary Care-A Perspective from the Keystone IV Conference
}

William L. Miller, MD, MA

Family physicians hunger in a time of excess. This article reviews the importance of healing relationships in the craft of family medicine and several of the forces that have undermined the ability to achieve effective healing relationships. Several directions forward are recommended and a promise shared. (J Am Board Fam Med 2016;29:S19-S23.)

Guest editors' note: This article was commissioned to help prepare attendees for participation in the G. Gayle Stephens Keystone IV Conference. It exposes how relationships are foundational to what promises personal physicians can and cannot make.

Keywords: Doctoring, Family Medicine, Family Physician, Health Care Delivery, Personal Physician, Population Health, Primary Care, Professionalism, Social Justice

Family physicians hunger in a time of excess. A glut of computer-based documentation, a fattening of corporate oversight and size, and rising consumer expectations for more services in less time stuff the work space of family medicine; yet, for too many family physicians and other primary care clinicians cultivating this craft in their local places, there remains a deep, longing ache in the pit of their guts. They hunger for fulfillment. Specifically, I propose that family physicians hunger for the nurturing embrace and satisfaction of meaningful relationships. I begin with a guided experience of the rhythms and heartbeats of relationship, position them in the context of family medicine, then high-

This article was externally peer reviewed.

Submitted 29 December 2015; revised 13 March 2016; accepted 17 March 2016.

From the Department of Family Medicine, Lehigh Valley Health Network, Allentown, PA; and the Department of Family Medicine, University of South Florida Morsani College of Medicine, Tampa.

Funding: none.

Conflict of interest: none declared.

Corresponding author: William L. Miller, MD, MA, Department of Family Medicine, Lehigh Valley Health Network, One City Center, PO Box 1806, Allentown, PA 18105 (E-mail: William.miller@lvhn.org). light and explore several of the challenges in cultivating healing relationships in the current health care delivery environment. This is followed by some brief suggestions for restoring relationships in primary care and relieving the hunger.

Pause for a moment; slow your breathing. As you read these words, relax your hand and prepare to tap the pulses of relationships.

Tap your finger on a hard surface at 280 taps/ minute. Listen and feel the sound and rapid movement. Embody theta brain wave activity (4 to 7 cycles per second), the rhythm activated by our deep relationship with self when doing mindfulness meditation. ${ }^{1}$ This same beat aided family medicine's ancestors, the early shamans, to journey into relationships with the spirit world on behalf of their patients seeking to restore them into the fellowship and membership of their intimate social and ecological worlds. ${ }^{2,3}$

Slow the tapping down to 140 taps/minute, just over 2 per second. Feel the beat-to-beat variability of a healthy fetal heart, a new life preparing for birth into an intimate membership, ready to belong. Smile as you recognize the reassurance of health communicated by this rhythm. 
Reduce the tempo to 70 taps/minute and experience the sound of a thriving adult as you imagine resting your head on another's chest, listening with your stethoscope, or enfolding another's hand with your finger on the pulse. Hold the intimate connection of this moment.

Diminish your cadence to 35 taps/minute. Listen to a grave tempo, the rhythm of a solemn funeral procession as a neighbor departs their living membership and joins the fellowship of memory and the spirit world. Pause in remembrance.

Now, with gusto, resume a 280-tap/minute rapping, and return, prestissimo, to relationship with time's story, to your current place, and now. Welcome home!

These are the many pulses of our developmental and contextual relationships in time, through time, and across place. The changing beats of your finger movements were consciously evident. What you may not have noticed is how your heart rate quickened and slowed with the changes in tempo. Material bodies are in relationship, simultaneously influencing and attuning. This is one of the secrets to how relationships facilitate healing. These are the rhythms and heartbeats of family medicine's craft.

Family medicine and primary care focus on health and the whole person, and healing relationships are an essential tool for achieving that goal. Healing relationships represent the ways in which 2 or more people (or other living beings such as a beloved pet and objects such as a special stuffed animal) are connected and interact over time and place such that health emerges. ${ }^{4}$ Health, as defined by Fine and Peters, ${ }^{5}$ is the ability to function in relationships appropriate to one's cultures and place in the life cycle, or, in the words of Kurt Stange, ${ }^{6}$ the ability to develop meaningful relationships and pursue transcendent purpose in a finite life. As Wendell Berry ${ }^{7}$ summarizes, "Health is membership," the significant belonging and participating that achieve the functions and abilities named by Fine and Peters and Stange.

A recent personal experience illustrates how difficult it has become to enact healing relationships in pursuit of health. Earlier this year, I was exploring some of the ways to do healing relationship work with family medicine residents. I reviewed how to identify high-yield moments by observing changes in breathing, facial expressions, eye movement, and posture; by listening for hesitations, turbulence, and changes in speech tempo ${ }^{8}$; and, as reminded by Gayle Stephens, ${ }^{9}$ to touch the part that hurts. We discussed how to use those same behaviors to better attune and modulate our clinical relationships. Then 1 of the residents challenged me. "How can I do this when I need to spend so much time, in the room, documenting in EPIC, our electronic health record?" The others present sighed and returned to their lunch. Some helpful suggestions ensued, but they were compromises, and everyone in the room knew it.

All family doctors know the demoralizing truth. Ask any family physician why they went into family medicine and "the rich relationships" is always 1 of their top 3 reasons, and they have many stories to support the answer. Their whole body brightens when they tell the stories. Ask these same family physicians how they are doing today and, especially if they are full-time clinicians, most of them become either angry or depressed and begin naming the problems and what else they believe they need. They hunger for identity, money, respect, time, more resources for patients, and joy. I suggest they really want their healing relationships restored. How were the relationships lost? What happened? What new questions arise because something happened? In what follows I name several of the changes that have disrupted our professional lives and relationships, raise some troubling questions, and hint at promising future directions.

Commodity-centered consumerism happened. Patients have been relabeled as "consumers" and clinicians as "providers." Really! This raises problematic questions. Do consumers always know best? Not always, and it is important to remember that relationships are where the creative tension between need and want creates health; patients present with concerns and wants and physicians identify explanations and needs. The relationship is where these are reconciled. When consumers leave the world of the well and enter the citizenship of the ill, much of their consumerism fades. Are family physicians and advanced practice clinicians "providers"? What does that mean exactly? It depends on intention and behavior. Providers sell commodities and services; they market and brand. Healers offer the gift of healing relationship; they covenant.

Employment happened. Within the past decade, the majority of family physicians shifted from independent practice to being employed by another, raising troubling questions. Who pays most primary care clinicians for their livelihood? Who sets 
the parameters of their work? In 2012, nearly $60 \%$ of family physicians were employed by some larger organization. ${ }^{10}$ Can these family medicine professionals serve 2 masters: their boss and their patients? Can they bite the hand that feeds them? All employed health professionals must remind themselves every day not who they work for but whom and what they serve, the relationships with patients and communities. This becomes a daily act of courage. This is also why it is critical to end the debt crisis for family medicine students and residency graduates as a means of supporting their courage.

Information technology happened. Nearly everyone now spends countless hours with their eyes gazing at various radiating screens of rapidly shifting, multitasked, linear digital data. We spend almost as much time in virtual worlds as in our physical ones, and this is also increasingly true for primary care clinicians as they scan and input templated screens and metrics while involved in patient care. What does it mean to rewire our brains in this way? What happens to our resilience and the ability to handle distress? What materializes when face time with patients is reduced? What happens to our thinking and decision making? Recall the 3 ways of thinking. The most common is fast thinking, with its often helpful heuristics composed of generalizations, distortions, deletions, and emotional leadership. ${ }^{11,12}$ Slow thinking engages disciplined rational thought usually used to justify the fast thinking. And then there is relational, systems thinking that combines the other 2 to discern patterns of relationship and patterns of meaning ${ }^{13}$ - the thinking of the generalist. More than ever, relational thought needs to be remembered and used to make sure our new technologies serve us and not vice versa. Now is the time to end fee-for-documentation and pay for (inappropriate) performance, to share our records with patients, and together, in relationship, to move toward goal-oriented, familycentered, clinical information systems so that technology is used to share power.

Workforce shortages, productivity focus, complexity of care, scope of care reduction, and bureaucracy (fee-for-documentation, pay for performance, regulations) happened, and with them the question, "If not family physicians, then who and/or what will do the work of primary care?" One possible answer, of course, is even more primary care fragmentation. Can primary care be successfully performed by advanced practice clinicians, ed- ucated patients, robots, and mobile technology? These are all a critical part of the solution, but none, on their own, are likely to successfully deliver high-value, high-performing primary care that achieves the triple aim of better health, better care, and lower cost along with the integrator function. ${ }^{14}$ Another, potentially more helpful, answer is primary care teams, but who is on the teams and who is in charge, and does it matter? With whom on the team does a patient have a healing relationship? It is hoped that the existence of interprofessional teams will expand the network of possibilities. For example, physicians often forget how important a receptionist can be in the healing process. Is there anything special about the physician-patient relationship? Yes, in depth and in breadth, but maybe not so much "special" as different from many other special healing relationships. Does integrating the 4 primary care core attributes of personal, first contact/accessible, comprehensive, and coordinated care really matter, or is the sum of the parts good enough? For example, can urgent care stand alone? I suspect not. Better is to integrate acute care into a personal, relationship-centered health team.

The rise of weak ties and decline of strong ties happened. ${ }^{15}$ The number of family and friends in whom to confide one's most personal matters has been declining by a third every 6 years since 2000; the number of people with no such confidante has doubled every 6 years over that same time period. ${ }^{16}$ Are intimate relationships important anymore? Are they worth the trouble? Or is social media enough? Clinicians and patients are more satisfied by relationships of attentive fidelity than by amassing commodities. ${ }^{17}$ Are deep relationships over-romanticized? Could there be a touch of narcissistic nostalgia? Possibly, and these questions represent some false choices. Health requires both strong and weak ties, neighborliness and abundance, along with individualism and creative restlessness.

It turns out that weak ties have much to offer improved health. Weak ties mobilize resources and options, enhance creativity and innovation, and help individuals get jobs. Strong ties are not always helpful; they are often exclusive, hierarchical, and authoritarian and a common source of developmental trauma. ${ }^{15}$ Everyone needs both. In a frightening, isolating, fragmenting, overpopulated world, everybody needs all the many kinds of helpful relationships they can get. Different relationships 
matter at different times. Family physicians juggle these differences in their personal lives and at work, where some clinical encounters are quick and superficial with people seen only once and some individuals met only sporadically, and others where patient and clinician are deeply embedded in each other's stories. All the relationship types matter. Family physicians are "relationship jugglers."

As personal physician healers, their great work is to co-create health by focusing on bodily integrity and meaningful membership. No more will they be the heroes of ancient myths; now they will serve as members of a heroic team of healers where the relationships within the team become critically important. But there is still a hero's journey. One must still risk and survive failure, say yes to adventure, learn to be comfortable with vulnerability. One must still enter the darkness where one develops imagination and the ability to empathize with the brokenness of others. One must still recognize and gain allies and still master the skills and competencies of medicine. Family medicine clinicians are no longer just personal family physicians. They are becoming a community of healing relationships generating communities of solution. They are emerging as a community with strong and weak relationships with their patient partners, with their practice colleagues, with themselves, with their health and medical neighborhood colleagues and services, with those in their communities, and with their local ecologies-and they are global. Family physicians activate healing and advocate within and across those relationships. They are each on the healer's voyage toward better membership, toward helping love grow, and in juggling these many relationships.

Millennials happened. They place greater emphasis on ensuring a fulfilling personal and family life than recent past generations; they are more likely to move for a better work and/or personal situation for self or a partner. Are they less committed to their profession? Are they less willing to sacrifice on behalf of their patients? Or are they better role models of health and wholeness? Don Berwick $^{18}$ wrote about the older professional myth of physician as hero using his father as an example. My father, like his, was also an exceptional general practitioner. But he believed in himself too much; he wore his hero's cape too often. His patients loved him, but too many were diminished in their own power as he made decisions for them rather than with them. I believe it is time to bury the physician as hero myth and the old professionalism. ${ }^{6,18}$ Thank you Millennials! You are now revealing ways to use the many cultural changes noted above to better serve healing relationships.

How can family medicine healers do their relationship craft in this world controlled by wealth and power? How do they survive and thrive in this crock pot of plutocracy? The science of how these healing relationships happen has come far and can help in addressing these questions. Attunement, intention, conditioning, and expectancy are critical qualities. The research by Scott et $\mathrm{al}^{19}$ demonstrated that valuing expressed through a nonjudgmental stance, personal resonance, and presence; appreciating power through partnering, explanation and self-management, and appropriate pushing; and abiding through continuity, especially at major health crises, caring actions, and not giving up are essential processes for healing relationships. Most healing occurs out in neighborhoods, not in practices. Thus the healer's role is to change expectancy; to activate, facilitate, teach, support, and co-create meaning; and to mobilize resources in ways that dramatically increase the chances for healing and health out there where people live and work. $^{20}$

In summary, the function of primary care is to activate, establish, and sustain primary healing relationships. Family medicine healers do this by effectively enacting the 4 core attributes of first contact/access, comprehensive, coordinated, and personal care ${ }^{21}$ throughout the full scope of primary care in sufficient quantity ( $40 \%$ to $50 \%$ of the clinical workforce) with a focus on health and mindfully embodying 5 simple rules of healing relationships derived from the research of Scott et $\mathrm{al}^{19}$ :

1. Find something you value in each colleague and patient you encounter.

2. Give your full attention in any interaction.

3. Try to strengthen and encourage every person you encounter.

4. Always respond and stay in dialog.

5. Never do all the relational work in any relationship.

Everyone seeks meaningful belonging and fulfillment. Be-long evokes extended social ties and feeling connected to a past and an imagined future, 
the flow of time. To be full and filled evokes how we shape and imbue our lives with meaning and purpose-health in our places.

I am a family physician and close with this promise: to always be present, as clinically competent partners, and to work with each patient partner, their family and friends, and our communities for better health. It is a collective promise by a personal, relationship-centered team. My individual promise is to ensure the collective one. This is a dream that will not sleep; a promise we will keep and use to fill our hunger.

\section{References}

1. Travis F, Shear J. Focused attention, open monitoring and automatic self-transcending: categories to organize meditations from Vedic, Buddhist and Chinese traditions. Conscious Cogn 2010;19:1110-8.

2. Winkelman M. Shamanism: the neural ecology of consciousness and healing. Westport, CT: Bergin and Garvey; 2000.

3. Vaitl D, Birbaumer N, Gruzelier J, et al. Psychobiology of altered states of consciousness. Psychol Bull 2005;131:98-127.

4. Miller WL, Crabtree BF. Healing landscapes: patients, relationships, and creating optimal healing places. J Altern Complement Med 2005;11(Suppl 1):S41-9.

5. Fine M, Peters JW. The nature of health: how America lost, and can regain, a basic human value. London: Radcliffe Publishing; 2007.

6. Stange KC. The power to advocate for health. Ann Fam Med 2010;8:100-7.

7. Berry W. Health is membership. In: Wirzba N, ed. The art of the commonplace: the agrarian essays of Wendell Berry. Berkeley, CA: Counterpoint Press; 2002.

8. Neighbour R. The inner consultation. 2nd ed. London: Radcliffe Publishing; 2005.
9. Stephens GG. The personal touch: the physician healer in modern society. J Kans Med Soc 1965;66: 237-9, 242.

10. Kane CK, Emmons DW. New data on physician practice arrangements: private practice remains strong despite shifts towards hospital employment. Chicago: American Medical Association Policy Research Perspectives; 2013: 1-16.

11. Kahneman D. Thinking, fast and slow. New York: Farrar, Straus, and Giroux; 2011.

12. Haidt J. The righteous mind: why good people are divided by politics and religion. New York: Vintage Books; 2012.

13. Suchman AL. A new theoretical foundation for relationship-centered care: complex responsive processes of relating. J Gen Intern Med 2006;21(Suppl 1):S40-4.

14. Berwick DM, Nolan TW, Whittington J. The triple aim: care, health, and cost. Health Aff (Millwood) 2008;27:759-69.

15. Granovetter M. Getting a job: a study of contacts and careers. 2nd ed. Chicago: University of Chicago Press; 1995.

16. Brashears ME. Small networks and high isolation? A reexamination of American discussion networks. Soc Networks 2011;33:331-41.

17. Brueggeman W. Sabbath as resistance: saying no to the culture of now. Louisville, KY: Westminster John Knox Press; 2014.

18. Berwick DM. The epitaph of profession. Br J Gen Pract 2009;59:128-31.

19. Scott JG, Cohen D, DiCicco-Bloom, Miller WL, Stange KC, Crabtree BF. Understanding healing relationships in primary care. Ann Fam Med 2008; 6:315-22.

20. Miller WL, Crabtree BF, Duffy MB, Epstein RM, Stange KC. Research guidelines for assessing the impact of healing relationships in clinical medicine. Altern Ther Health Med 2003;9(Suppl 3):80A-95A.

21. Starfield B. Primary care: balancing health needs, services, and technology. New York: Oxford University Press; 1998. 